\title{
EXPLORATION OF MECHANICAL PROPERTIES OF MODIFIED NANOMETER CONCRETE
}

\author{
Yang Lei \\ Henan Information and Statistics Vocational College, Zhengzhou, Henan 450008, China \\ Email: leiyangly2013@126.com
}

\begin{abstract}
To study the mechanical properties of modified nanometer concrete, several different nanomaterials were first listed, then these nanomaterials were added into concrete respectively, and the compressive strengths and flexural strengths of concretes in each case were calculate. Subsequently, the obtained data were drawn into a broken line graph, with the abscissa as the incorporation amount of polymer materials and the ordinate as the compressive strength and flexural strength of concrete respectively. It can be concluded from the image that both mechanical properties were improved with the increase of incorporation amount of nanometer material. In particular, when the incorporation amount reached $1 \%$, the compressive strength and flexural strength of both modified ordinary concrete and modified fly ash concrete reached the maximum value of 50-60 Mpa. Consequently, the use of nanomaterials can improve the mechanical properties of concrete.
\end{abstract}

Keywords: Nanomaterials, Concrete, Mechanical Property, Workability, Compressive Strength, Flexural Strength.

\section{Introduction}

Due to the advantages of low cost, easy access to raw materials and simple construction, concrete is widely applicable for civil engineering, and it is also one of the largest construction materials in terms of quantity and output. However, in the initial stage of concrete development, the main concern of scholars is the strength of concrete. With the development and use of concrete, in the nearly 200 -year history of concrete application, reinforced concrete structures often fail to reach the design life of the structure, and scholars initially believed that it was caused by poor construction and non-standard design [1].

However, with the development of concrete, scholars have found that the damage of reinforced concrete structure is not caused by its insufficient strength, but by the influence of various adverse environments on concrete and its poor durability. Therefore, relevant scholars gradually put the research into the durability of concrete. Fai Uddin summarized the research results of concrete in the 20th century [2]

He believed that the research focus of concrete in the 21st century should not be on the strength of concrete, but on the durability of concrete. There were many factors affecting concrete durability, the main factors can be divided into internal factors and external factors. Internal factors mainly referred to the internal materials that constituted concrete, including water-cement ratio, cement dosage and admixture, etc. And the external factors were the external environment during curing, including temperature and loading time. It was necessary to study and improve the durability of concrete, because its external environment (atmosphere, water, etc.) was difficult to change. Scholars hoped to change the internal factors of concrete by adding additives, so as to improve its durability to resist external harsh environment. In summarizing the durability of concrete, Mehta [3] considered that the corrosion of rebars, the freeze-thaw damage in cold weather and the erosion under salt environment were the main problems of concrete durability. It can be concluded that salt freezing damage was a major cause for concrete durability [4].

According to reports, by the end of the 1990s, more than half of the bridges in the United States were damaged by the erosion of different degrees of snowmelt agent. Among these damaged bridges, the bearing capacity of nearly $80 \%$ was significantly reduced, making it insufficient [5].

Meanwhile, the United States government has spent nearly 150 billion dollars to repair the damaged bridge structure. Coincidentally, the United Kingdom has also suffered greatly [6].

From the 1970 s to the 1980s, the British government spent twice as much to repair damaged reinforced concrete bridges, which was twice as large as the original structure at the beginning of this century [7]. 
With the development of nanotechnology, nanomaterials have gradually become one of the excellent materials applied in various fields due to their excellent properties (large surface area, small scale and high surface energy) [8].

At the same time, with the development of concrete, concrete research is also gradually developing towards the micro direction [9]. Improving the performance of concrete through nanotechnology has become one of the important development directions. However, there are few studies on nanomaterials modified concrete, and nanomaterials have no clear principle and method for the modification of concrete. Therefore, it is of great significance to find appropriate methods to study nano-modified concrete [10].

\section{Literature Review}

Nanomaterials are concepts that were introduced in a lecture at the American physical society called "there's a lot of room at the bottom" by Richard Feynman, a famous physicist and two-time Nobel laureate Although nanometer was not proposed at that time, the basic concept of nanometer was actually proposed. He predicted that if people could control the ordering of objects on a small scale, they would get many substances with special properties. Nanometer was also proposed by Japanese professor Norio Taniguchi. With the invention of Scanning Tunneling Microscope (STM), scientists were able to observe and manipulate individual atoms for the first time. Since 1959, nanotechnology has only been known for about 60 years. Nanotechnology has become a part of people's life. Due to their excellent properties, nanomaterials have become a hot topic in the field of materials in the 21st century. Nanomaterials are ultrafine materials that have at least one dimension of nanometer size in the threedimensional space or that are composed of them as basic units. Its size is on the nanometer scale, with a diameter of $0.1 \sim 100 \mathrm{~nm}$. Its size is larger than that of atom and smaller than that of micro powder, which is the size of transition region between atom and macro object. Nanomaterials include metal, nonmetal, organic, inorganic and biological powder materials [11]. Due to their small size, nanomaterials have surface effect, volume effect, size effect and macroscopic quantum tunneling effect.

Relevant studies showed that pozzolanic activity of nano - $\mathrm{SiO}_{2}$ (NS) was much higher than that of silica powder. Incorporation of NS resulted in shortened setting time and reduced fluidity of slurry and significantly improved early strength of concrete. The pozzolanic reaction absorbed a large amount of $\mathrm{Ca}(\mathrm{OH})_{2}$, which promoted the hydration of cement, increased the heat release rate at the beginning of hydration, and improved the microstructure of cement slurry, making cement more uniform and compact.
The incorporation of Nanometer $\mathrm{CaCO}_{3}(\mathrm{NC})$ into the concrete played a role in hydration, physical filling, and formation of crystal nucleus, it accelerated the early hydration speed of clinker, increased the cement compaction and reduced the porosity of the concrete, thereby improving the compressive strength of cement stone [12].

Zhang's study showed that concrete mixed with slag powder and nano - $\mathrm{SiO}_{2}$ improved the pore distribution of concrete, accelerated the formation of $\mathrm{C}-\mathrm{S}-\mathrm{H}$ gel, and enhanced the splitting tensile strength of concrete [13].

Adak et al. conducted research on mechanical properties, rheological properties and durability of self-compacting concrete [14]. It was found that the addition of nano - $\mathrm{SiO}_{2}$ could improve the compressive strength, splitting strength, flexural strength and elastic modulus of concrete. However, when the content of cement exceeded 4\%, the mechanical properties of nanomaterials decreased due to the unstable reaction caused by the collision of nanomaterials.

Nattaj believed that the improvement of the early strength of high-performance concrete by nano $\mathrm{SiO}_{2}$ was the most obvious. Moreover, with the addition of nano - $\mathrm{SiO}_{2}$, the critical crack opening displacement, fracture energy, crack initiation fracture toughness, instability fracture toughness, effective crack length and other fracture parameters of concrete showed a trend of increasing first and then decreasing. With a certain amount of steel fiber composite admixture, the mechanical properties of concrete can achieve better lifting effect [15].

\section{Methodology}

\subsection{Study on workability of nano-modified concrete}

Workability is an important index to measure the fluidity of concrete, which has great influence on the construction, mechanical properties and durability of concrete. When the nano materials was applied in modified concrete, due to its large surface area and surface energy characteristics, nanomaterials would absorb a large amount of free water, resulting in too little water in the concrete, which can't be fully mixed with cement to form cement slurry, so that the void between coarse aggregate and fine aggregate in the concrete can't be well filled, and the coarse aggregate and fine aggregate can't be well wrapped to lubricate it. Therefore, the cohesiveness degree of the concrete is lowered, so that the concrete is not formed well, causing large defects, thereby lowering the strength and durability of the concrete. If the workability of the concrete is too small or too large, the concrete will have corresponding defects, the concrete can't reach the corresponding strength and durability of the design, and the method of 
improving the performance of the nano-modified concrete can't achieve, the performance of the concrete is reduced, its cost is increased, and the meaning of nano-modified concrete doesn't exist. So the first task of research on nano-modified concrete is its workability.

\subsection{Mechanical properties test of nanometer concrete}

Test method:

The compressive strength and flexural strength tests were conducted in accordance with relevant test specifications. Concrete was divided into nine groups according to the variety and adulterate amount.
Three specimens were tested in each group and the average value was taken as the test strength value. In the same group, if there was a specimen with a difference of $15 \%$ or more, the mean strength value of the other two specimens would be taken as the strength value. And if there was a difference of more than $15 \%$ between two specimens, the test result of this group would be invalid.

Test results:

The compressive strength test of nanometer cement concrete used standard cube specimen of $150 \times 150 \times 150 \mathrm{~mm}$. During the test, the loading rate of the press was $0.8 \mathrm{Mpa} / \mathrm{s}$; in the bending strength, $150 \times 150 \times 150 \mathrm{~mm}$ prism specimens and three-point loading method were adopted.

During the test, the loading rate was $0.08 \mathrm{Mpa} / \mathrm{s}$, and the test results were as follows:

Table 1. Test results of mechanical properties of different nano-concrete

\begin{tabular}{cccccc}
\hline $\begin{array}{c}\text { Specimen } \\
\text { Type }\end{array}$ & $\begin{array}{c}\text { Amount of } \\
\text { admixture } \\
/ \%\end{array}$ & $\begin{array}{c}\text { Compressive } \\
\text { strength } \\
\text { /Mpa }\end{array}$ & $\begin{array}{c}\text { Increase } \\
\text { ratio } \\
/ \%\end{array}$ & $\begin{array}{c}\text { Rupture } \\
\text { strength } \\
\text { /Mpa }\end{array}$ & $\begin{array}{c}\text { Increase } \\
\text { ratio } \\
/ \%\end{array}$ \\
\hline PC & 0 & 64.13 & 0 & 7.23 & 0 \\
NS05C & 0.5 & 66.94 & 4.38 & 7.57 & 4.70 \\
NS10C & 1 & 67.68 & 5.54 & 7.86 & 8.71 \\
NS15C & 1.5 & 69.16 & 7.84 & 8.17 & 8.00 \\
NS20C & 2 & 65.64 & 2.35 & 7.82 & 8.02 \\
NC05C & 0.5 & 65.29 & 1.81 & 7.46 & 3.18 \\
NC10C & 1 & 68.19 & 6.33 & 7.88 & 8.99 \\
NC15C & 1.5 & 66.07 & 3.03 & 7.26 & 6.78 \\
NC20C & 2 & 63.20 & -1.45 & 7.77 & 0.41 \\
\hline
\end{tabular}

Nanomaterials can be used to fill in the tiny interstices in concrete, improve the compactness of concrete and improve the mechanical properties of concrete. Nano - $\mathrm{SiO}_{2}$ has pozzolanic activity of nano - $\mathrm{CaCO}_{3}$, and the mechanical properties of concrete increased greatly after the addition of nano- SiO2. When the nano $-\mathrm{SiO}_{2}$ content was $1.5 \%$, the growth rates of compressive strength and flexural strength of concrete were $7.84 \%$ and $13.00 \%$ respectively.

The growth rates of compressive strength and flexural strength of concrete with $1.0 \%$ nanometer $\mathrm{CaCO}_{3}$ were $6.33 \%$ and $8.99 \%$, respectively.

From the point of view of mechanical properties, $1.5 \% \mathrm{SiO}_{2}$ and $1.0 \% \mathrm{CaCO}_{3}$ were the optimal dosage for the two nanomaterials.

\subsection{Study of the flexural compression ratio of concrete}

Regarding the relationship between compressive strength and flexural strength of concrete, there are many empirical formulas for reference, in which the correlation is different.

The American Portland cement association proposed the relationship between the compressive strength and flexural strength of cylindrical concrete specimens:

$$
f_{f}=0.0934 f_{c u}+1.32
$$

The American concrete commission proposed a classic relationship:

$$
f_{f}=0.62 \sqrt{f_{c u}}
$$

The empirical relationship proposed by the road committee of Japan cement association was as follows: 


$$
f_{f}=0.128 f_{c u}+1.990
$$

The research institute of highway science of the ministry of communications of China established the relationship between $28 \mathrm{~d}$ compressive strength and flexural strength of concrete:

$$
f_{f}=0.415 f_{c u}^{0.725}
$$

Some scholars pointed out that the calculation of the flexural strength should be based on the actual materials used in the project and the previous empirical data to establish the correlation between the two.

The strength of cement slurry and aggregate determined the compressive strength of concrete, while the flexural and tensile strength depended on the strength of the interface transition zone. Related experimental studies showed that the degree of chemical reaction of nano-materials with $\mathrm{Ca}(\mathrm{OH})_{2}$ in the cement slurry body was lower than that of $\mathrm{Ca}$ $(\mathrm{OH})_{2}$ in the transition zone of concrete interface, thus leading to the research on the flexural ratio of nanometer cement concrete.

Flexural ratio of concrete is the ratio of flexural strength to compressive strength, which is an important index of ductility. In practical projects, it is often necessary to reduce water-cement ratio and increase cement dosage to obtain higher flexural strength of concrete. The improvement rate of flexural strength brought by reducing water-cement ratio and increasing cement dosage is not as large as compressive strength. Therefore, it will lead to excessive compressive strength of concrete. The flexural strength ratio of nano-concrete can be used as an important parameter to measure the correlation between compressive strength and flexural strength of nano-concrete and to explore the effect of nano-materials on the mechanical properties of concrete.

$$
\lambda=\frac{f_{f}}{f_{c u}}
$$

Among them, $f_{f}$ represents the flexural strength of concrete (MPa); and $f_{c u}$ represents the compressive strength of concrete cube (MPa).

With the addition of nano - $\mathrm{SiO}_{2}$, the flexural compression ratio of concrete increased with the increase of the amount of admixture. After the addition of nanometer $\mathrm{CaCO}_{3}$, the concrete's flexural compression ratio also increased, and it generally increased first and then decreased with the increase of addition. When the amount of admixture of nanometer $\mathrm{CaCO}_{3}$ exceeded $1.0 \%$, the flexural compression ratio of concrete decreased with the increase of addition.

The reason for this difference was that nano $\mathrm{SiO}_{2}$ had high pozzolanic activity, and it can react with $\mathrm{Ca}(\mathrm{OH})_{2}$ in the interface transition zone around the concrete aggregate, reduce the number of
$\mathrm{Ca}(\mathrm{OH})_{2}$ crystals, and improve the orientation of the interface transition zone, so that the growth rate of flexural strength of concrete was greater than that of compressive strength. Nano- $\mathrm{CaCO}_{3}$ has no pozzolanic activity, but nano- $\mathrm{CaCO}_{3}$ can fill the void in the transition zone and deposit $\mathrm{Ca}^{+}$ions around it. From the reversibility analysis of chemical reaction, nano $-\mathrm{CaCO}_{3}$ can reduce the precipitation rate of $\mathrm{Ca}$ $(\mathrm{OH})_{2}$, so as to improve the flexural strength of concrete and increase the flexural ratio of concrete.

When the content of nano - $\mathrm{CaCO}_{3}$ exceeded a certain amount, excessive acicular ettringite (AFT) was generated in cement hydration reaction. Excessive deposition of calcium carboaluminate hydrate and acicular AFT around the transition zone was unfavorable to the flexural strength of concrete, resulting in a decrease in the flexural pressure ratio.

\subsection{Mechanical properties of nano - $\mathrm{SiO2}$ modified concrete}

Nano- $\mathrm{SiO}_{2}$ is a common nano-material, which will have a certain impact on the early strength of concrete when mixed with it. In this study, the compressive strength and flexural strength of nanomodified concrete at $3 \mathrm{~d}, 7 \mathrm{~d}$ and $28 \mathrm{~d}$ were tested.

The compressive strength and flexural strength of nano $-\mathrm{SiO}_{2}$ modified ordinary concrete were shown in Figure 1 and Figure 2.

The compressive strength and flexural strength of nano $-\mathrm{SiO}_{2}$ modified fly ash concrete were shown in figure 3 and figure 4.

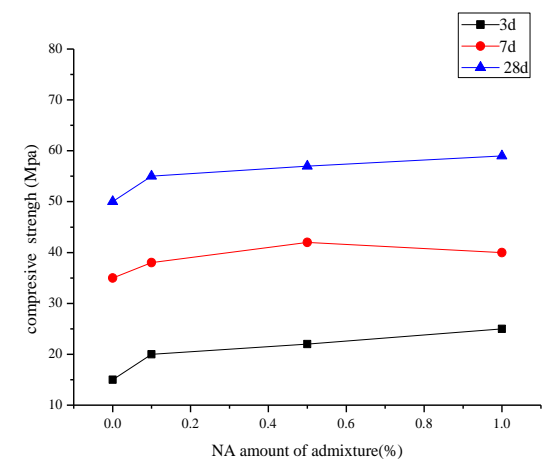

Figure 1. Compressive strength of nano - $\mathrm{SiO}_{2}$ modified concrete

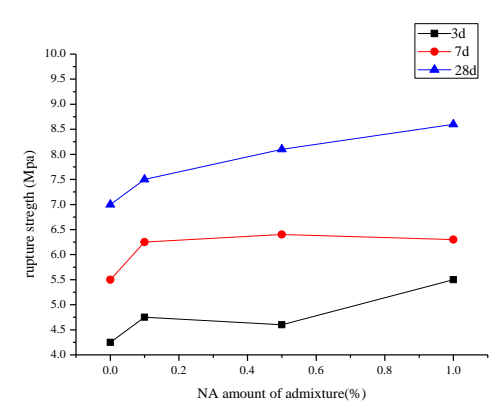

Figure 2. Flexural strength of nano - $\mathrm{SiO}_{2}$ modified concrete 
According to figure 1 and figure 2, the compressive strength and flexural strength of nano $\mathrm{SiO}_{2}$ modified concrete increased with the increase of nano $-\mathrm{SiO}_{2}$ content. When the nano- $\mathrm{SiO}_{2}$ content reached $1 \%$, the compressive strength and flexural strength of $3 \mathrm{~d}, 7 \mathrm{~d}$ and $28 \mathrm{~d}$ reached the maximum. Compared with the reference group's compressive strength of $50.12 \mathrm{MPa}$, the $28 \mathrm{~d}$ compressive strength reached $60.57 \mathrm{MPa}$ when the nano $-\mathrm{SiO}_{2}$ content reached $1 \%$, and its compressive strength increased by $20.1 \%$.

Compared with the flexural strength of $7.12 \mathrm{MPa}$ of the reference group at $28 \mathrm{~d}$, the compressive strength reached $8.95 \mathrm{MPa}$ when the nano $-\mathrm{SiO}_{2}$ content reached $1 \%$, and its compressive strength increased by $25.8 \%$.

Among them, the early strength of nano - $\mathrm{SiO}_{2}$ modified concrete was stronger with the increase of amount of admixture.

In 3d, compared with $15.21 \mathrm{MPa}$ in the reference group, the compressive strength reached $23.25 \mathrm{MPa}$ and its compressive strength increased by $54.2 \%$ when the nano $-\mathrm{SiO}_{2}$ content reached $1 \%$.

Compared with the flexural strength of the reference group (4.36 $\mathrm{MPa})$, when the nano - $\mathrm{SiO}_{2}$ content reached $1 \%$, the flexural strength reached $5.37 \mathrm{MPa}$ and the flexural strength increased by 23.3\%. Therefore, nano - $\mathrm{SiO}_{2}$ modified concrete can improve the early strength to some extent. However, in $3 d$, when the content was $0.5 \%$, the flexural strength decreased compared with $0.1 \%$.

The reason may be that the dispersion of nanomaterials is not uniform with the increase of amount of admixture, resulting in the concentration of nano $\mathrm{SiO}_{2}$. However, the reason for the experimental error can't be excluded.

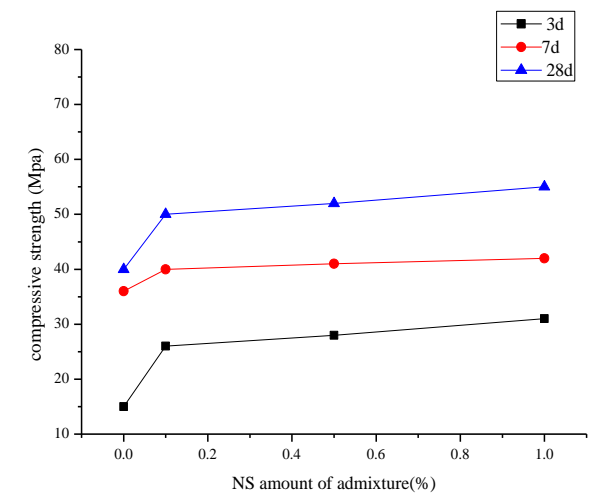

Figure 3. Compressive strength of nano - $\mathrm{SiO}_{2}$ modified fly ash concrete

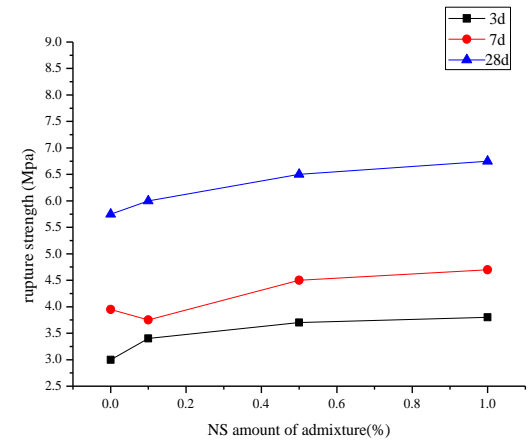

Figure 4. Rupture strength of nano - $\mathrm{SiO}_{2}$ modified fly ash concrete

According to figure 3 and figure 4 , the compressive strength and flexural strength of nano $\mathrm{SiO}_{2}$ modified fly ash concrete increased with the increase of nano - $\mathrm{SiO}_{2}$ content. When the nano - $\mathrm{SiO}_{2}$ content reached $1 \%$, the compressive strength and flexural strength of $3 d, 7 d$ and $28 d$ reached the maximum. Compared with the reference group's compressive strength and flexural strength of 45.56 $\mathrm{MPa}$ and $5.78 \mathrm{MPa}$ at $28 \mathrm{~d}$, when the nano $-\mathrm{SiO}_{2}$ content reached $1 \%$, its compressive strength and flexural strength reached 53.34 $\mathrm{MPa}$ and $6.85 \mathrm{MPa}$, which increased by $16.7 \%$ and $18.7 \%$ respectively. In $3 \mathrm{~d}$, compared with the compressive strength and flexural strength of the reference group, the compressive strength and flexural strength were increased by $75.5 \%$ and $30.2 \%$, respectively.

Compared with nano - $\mathrm{SiO}_{2}$ modified ordinary concrete, nano - $\mathrm{SiO}_{2}$ modified fly ash concrete had a poor effect. It may be that the addition of fly ash into cement reduces the strength of concrete at the early stage, or it may be that fly ash may react with nano $\mathrm{SiO}_{2}$ in an unknown way and affect its modification effect. However, nano - $\mathrm{SiO}_{2}$ modified fly ash concrete can improve the early strength to a certain extent, which can solve the problem of insufficient early strength of fly ash concrete and improve the working strength of concrete to some extent.

\subsection{Mechanical properties of nano - Al203 modified concrete}

Nano - $\mathrm{Al}_{2} \mathrm{O}_{3}$ is also a common nanometer material, which can be added into concrete to improve the early strength of concrete. In this study, the compressive strength and flexural strength of nano-modified concrete at $3 \mathrm{~d}, 7 \mathrm{~d}$ and $28 \mathrm{~d}$ were tested.

The compressive strength and flexural strength of nano - $\mathrm{Al}_{2} \mathrm{O}_{3}$ modified ordinary concrete were shown in figure 5 and figure 6 . And the compressive strength and flexural strength of nano - $\mathrm{Al}_{2} \mathrm{O}_{3}$ modified fly ash concrete were shown in figure 7 and figure 8. 


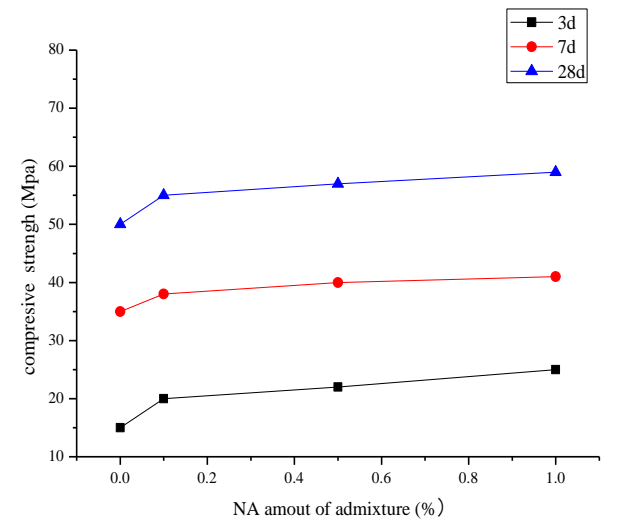

Figure 5. Compressive strength of nano $-\mathrm{Al}_{2} \mathrm{O}_{3}$ modified ordinary concrete

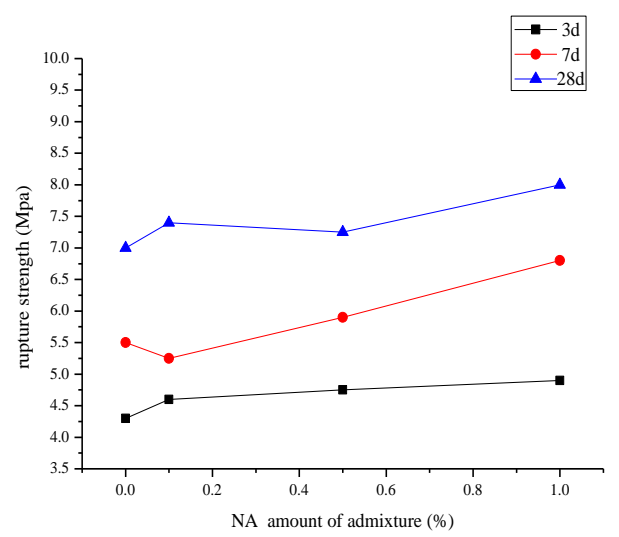

Figure 6. Rupture strength of nano $-\mathrm{Al}_{2} \mathrm{O}_{3}$ modified ordinary concrete

As can be seen from figure 5 and figure 6, the compressive strength and flexural strength of nano $\mathrm{Al}_{2} \mathrm{O}_{3}$ modified concrete increased with the increase of nano - $\mathrm{Al} 2 \mathrm{O} 3$ content. When the nano - $\mathrm{Al}_{2} \mathrm{O}_{3}$ content reached $1 \%$, the compressive and flexural strength of $3 \mathrm{~d}, 7 \mathrm{~d}$ and $28 \mathrm{~d}$ reached the maximum.

Compared with the reference group's compressive strength of $50.12 \mathrm{mpa}$, the compressive strength of $28 \mathrm{~d}$ reached $55.45 \mathrm{MPa}$ and its compressive strength increased by $12.8 \%$ when the nano $-\mathrm{Al}_{2} \mathrm{O}_{3}$ content reached $1 \%$. Compared with the reference group's flexural strength of $5.12 \mathrm{MPa}$ at $8 \mathrm{~d}$, when the nano - $\mathrm{Al}_{2} \mathrm{O}_{3}$ content reached $1 \%$, its flexural strength reached $5.93 \mathrm{MPa}$ and its compressive strength increases by $16.4 \%$.

Among them, the early strength of nano $-\mathrm{Al}_{2} \mathrm{O}_{3}$ modified concrete was stronger with the increase of amount of admixture. In 3d, compared with the reference group's compressive strength of 15.21 $\mathrm{MPa}$, when the nano $-\mathrm{Al}_{2} \mathrm{O}_{3}$ content reached $1 \%$, its compressive strength reached $21.96 \mathrm{MPa}$, and its compressive strength increased by $44.4 \%$. When the nano $-\mathrm{Al}_{2} \mathrm{O}_{3}$ content reached $1 \%$, the flexural strength increased by $14.4 \%$ compared with the flexural strength of the reference group.
Therefore, nano - $\mathrm{Al}_{2} \mathrm{O}_{3}$ modified concrete had some improvement on the early strength and the strength of concrete. At the same time, the mechanical properties of nano $-\mathrm{Al}_{2} \mathrm{O}_{3}$ were poor compared with that of nano- $\mathrm{SiO}_{2}$.

The reason may be that nano $-\mathrm{Al}_{2} \mathrm{O}_{3}$ was more difficult to disperse than nano - $\mathrm{SiO}_{2}$. Nano $-\mathrm{Al}_{2} \mathrm{O}_{3}$ had a larger particle size and smaller specific surface area than nano $-\mathrm{SiO}_{2}$.

In addition, it was also possible that the two nanomaterials played different roles in the hydration reaction due to their different materials.

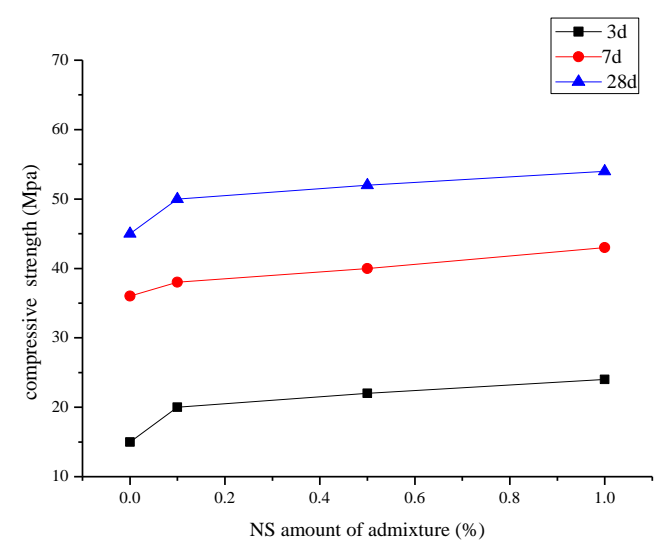

Figure 7. Compressive strength of nano $-\mathrm{Al}_{2} \mathrm{O}_{3}$ modified fly ash concrete

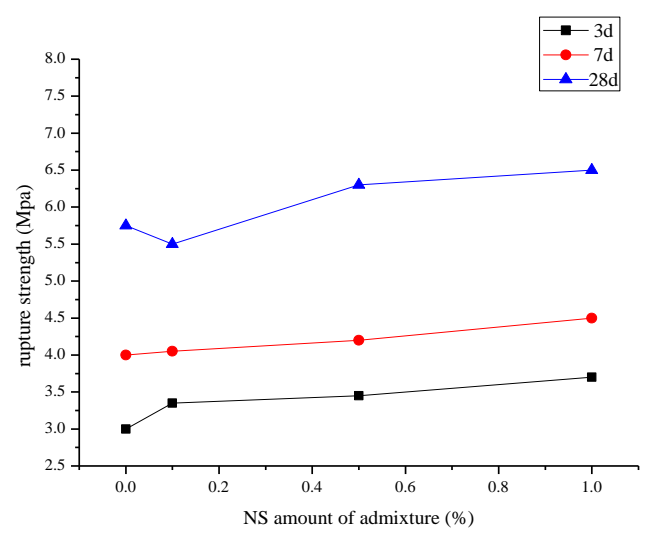

Figure 8. Rupture strength of nano $-\mathrm{Al}_{2} \mathrm{O}_{3}$ modified fly ash concrete

As can be seen from figure 7 and figure 8, the compressive strength and flexural strength of nano $\mathrm{Al}_{2} \mathrm{O}_{3}$ modified fly ash concrete increased with the increase of nano - $\mathrm{Al}_{2} \mathrm{O}_{3}$ content.

When the nano $-\mathrm{Al}_{2} \mathrm{O}_{3}$ content reached $1 \%$, the compressive strength and flexural strength of $3 d, 7 d$ and $28 \mathrm{~d}$ reached the maximum.

Compared with the compressive strength and flexural strength of the reference group, the compressive strength and flexural strength of $28 \mathrm{~d}$ increased by $10.2 \%$ and $11.6 \%$ when the nano $\mathrm{Al}_{2} \mathrm{O}_{3}$ content reached $1 \%$. In $3 \mathrm{~d}$, compared with the compressive strength and flexural strength of the reference group, the compressive strength and 
flexural strength were increased by $61.3 \%$ and $26.7 \%$, respectively.

Therefore, nano - $\mathrm{Al}_{2} \mathrm{O}_{3}$ modified fly ash concrete had certain improvement on the early strength, which can solve the problem of insufficient early strength of fly ash concrete to a certain extent and improve the working strength of concrete. At the same time, the mechanical properties of fly ash concrete modified by nano - $\mathrm{SiO}_{2}$ were relatively poor.

The reason may be that nano - $\mathrm{Al}_{2} \mathrm{O}_{3}$ was more difficult to disperse than nano - $\mathrm{SiO}_{2}$. And the nano $\mathrm{Al}_{2} \mathrm{O}_{3}$ had a larger particle size and smaller specific surface area than nano - $\mathrm{SiO}_{2}$. It was also possible that the two nanomaterials played different roles in the hydration reaction due to their different materials.

\section{Results and Discussion}

\subsection{Comparison of mechanical properties of nano - modified concrete}

According to the results in the Section 3 , the addition of nano $-\mathrm{SiO}_{2}$ and nano $-\mathrm{Al}_{2} \mathrm{O}_{3}$ into concrete and fly ash concrete can improve the mechanical properties of concrete.

And with the increase of content of nanomaterials, the mechanical properties of nanometer modified concrete and fly ash concrete were also improved.

Therefore, it can be concluded that the optimal content of nanomaterials for improving the mechanical properties of concrete and fly ash concrete is $1.0 \%$.

In this Section, by comparing the mechanical properties of two kinds of nano-modified concrete and fly ash concrete with the nano-material content of $1.0 \%$, the differences of flexural property and compressive property between the two kinds of concrete can be obtained.

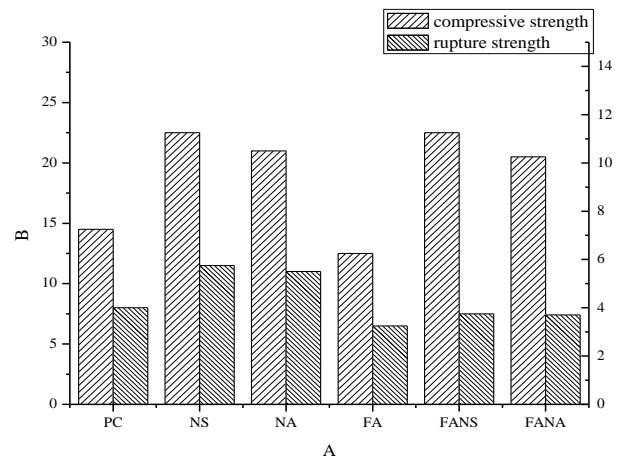

Figure 9. Mechanical properties of $3 d$ concrete

Figure 9 showed the compressive strength and flexural strength of modified concrete and fly ash concrete with a content of $1 \%$ nanometer material after $3 d$ standard curing. It can be concluded from the figure that, after standard curing in $3 d$, the compressive strength and flexural strength of nano $\mathrm{SiO}_{2}$ modified ordinary concrete and fly ash concrete were better than those of nano - $\mathrm{Al}_{2} \mathrm{O}_{3}$ modified ordinary concrete and fly ash concrete.

Among them, after the modification of nano - $\mathrm{SiO}_{2}$ and nano - $\mathrm{Al}_{2} \mathrm{O}_{3}$, the compressive strength of concrete increased by $54.2 \%$ and $44.4 \%$ respectively, and the flexural strength increased by $23.3 \%$ and $14.1 \%$ respectively.

As for the modified fly ash concrete, its compressive strength increased by $75.2 \%$ and $61.3 \%$, and its flexural strength increased by $30.2 \%$ and $26.7 \%$, respectively.

Therefore, nano-modification can improve the early strength of fly ash.

After 7d standard curing, the compressive property and flexural property of concrete and fly ash concrete with nano $-\mathrm{SiO}_{2}$ and nano $-\mathrm{Al}_{2} \mathrm{O}_{3}$ content of $1 \%$ were shown in figure 10 .

The compressive strength and flexural strength of modified concrete and fly ash concrete for $7 d$ was higher than that of unmodified concrete.

At the same time, the modification effect of nano $\mathrm{SiO}_{2}$ was slightly better than that of nano $-\mathrm{Al}_{2} \mathrm{O}_{3}$, and its effect was lower than that of $3 \mathrm{~d}$. Moreover, it can be concluded that the improvement effect of compressive and flexural properties of nano - $\mathrm{SiO}_{2}$ and nano - $\mathrm{Al}_{2} \mathrm{O}_{3}$ modified fly ash concrete was slightly better than that of ordinary concrete.

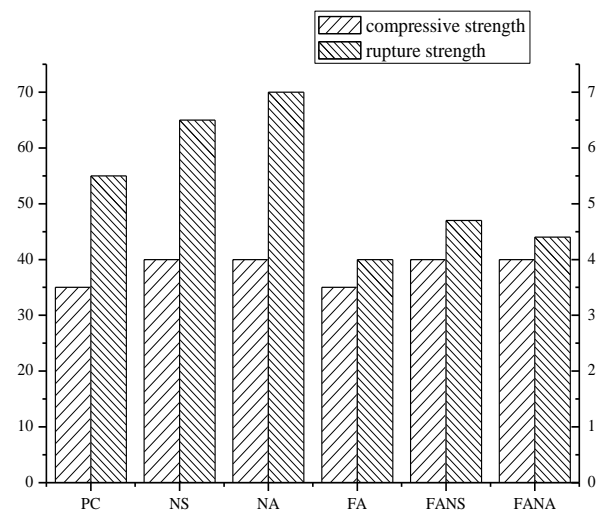

Figure 10. Mechanical properties of $7 d$ concrete

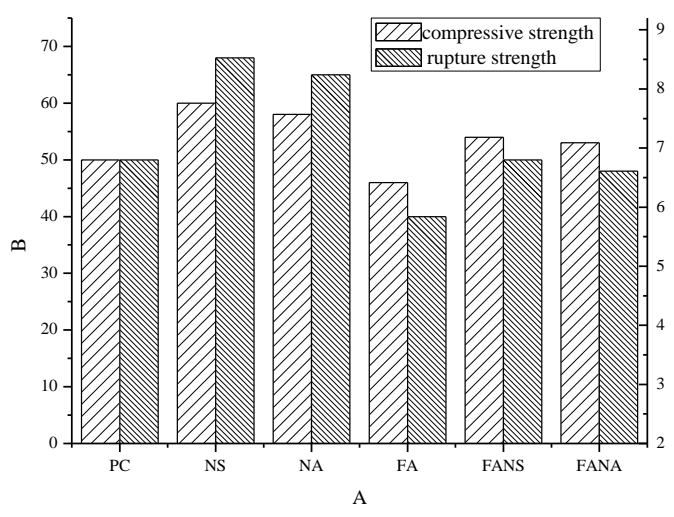

Figure 11. Mechanical properties of $28 d$ concrete 
Figure 10 showed the compressive strength and flexural strength of modified concrete and fly ash concrete with a content of $1 \%$ nanometer material after 28d standard curing.

As shown in the figure, the compressive strength and flexural strength of ordinary concrete and fly ash concrete modified by nano $-\mathrm{SiO}_{2}$ and nano $-\mathrm{Al}_{2} \mathrm{O}_{3}$ were improved to some extent after $28 \mathrm{~d}$ standard curing. After the modification of nano - $\mathrm{SiO}_{2}$ and nano $-\mathrm{Al}_{2} \mathrm{O}_{3}$, the compressive strength of concrete increased by $20.1 \%$ and $12.8 \%$ respectively, and the flexural strength increased by $25.8 \%$ and $16.4 \%$ respectively.

And the compressive strengths of the modified fly ash concrete were increased by $16.7 \%$ and $10.2 \%$ respectively, and flexural strengths were increased by $18.7 \%$ and $11.6 \%$ respectively.

Therefore, the modification effect of nano - $\mathrm{SiO}_{2}$ was better than that of nano $-\mathrm{Al}_{2} \mathrm{O}_{3}$, and the improvement effect of the flexural strength of nanomodified concrete was better than that of its compressive strength.

\subsection{Mechanical properties of $\mathrm{GO} / \mathrm{r}$ GO modified cement mortar}

Graphene (rGO) is a new two-dimensional carbon material with good mechanical, thermal and electrical properties. It is one of the nanomaterials with the best overall performance.

The composite of graphene with other materials can improve the comprehensive performance of matrix materials. At present, great progress has been made in the research of graphene cement matrix composites. However, due to the poor dispersion of $\mathrm{GO} / \mathrm{rGO}$ in aqueous solution, it is difficult to make $\mathrm{GO} / \mathrm{r}$ GO solution with high concentration, so its role in cement slurry is limited. In this study, the influence of $\mathrm{GO} / \mathrm{rGO}$ on cement mortar was investigated by $\mathrm{GO} / \mathrm{rGO}$ solution with low concentration.

After the addition of graphene oxide, the mechanical strength of the mortar was generally improved. When $0.12 \%$ GO was added, the $3 d$ compressive strength increased from 21.19 MPa to 26.54 $\mathrm{MPa}$, which increased by $30.8 \%$. The $7 \mathrm{~d}$ compressive strength increased from $31.25 \mathrm{MPa}$ to $35.99 \mathrm{MPa}$, which increased by $15.17 \%$.

And the $28 \mathrm{~d}$ compressive strength also increased by $6.9 \%$. The early $3 \mathrm{~d}$ flexural strength increased by $7.9 \%$, the early $7 \mathrm{~d}$ flexural strength increased by $6.5 \%$, and the early $28 \mathrm{~d}$ flexural strength increased by $26.8 \%$. It can be found from the data that GO increases the compressive strength of cement mortar in the early stage, but less in the later stage. It can be concluded that GO plays a certain role in promoting the hydration of cement in the early stage, but its flexural strength doesn't change much in the early stage, conversely, it increases greatly in the later stage.
The reason may be that the dispersion of GO in cement mortar was not uniform, and the early cement mortar was in the hydration reaction period, and the hydration degree of cement in each part was different. As the amount of graphene added gradually increased from 0 to $0.12 \%$, the $3 d, 7 d$, and 28d flexural strength and compressive strength of the hardened mortar increased. As a reinforcing material, rGO can improve the mechanical properties of cement-based materials. The $3 \mathrm{~d}$ flexural strength increased by $0.92 \%$ and the compressive strength by $36.7 \%$. The 28d flexural strength increased by $3.68 \%$ and the compressive strength increased by $16.6 \%$. This indicated that graphene nanomaterials can improve the mechanical properties of cement.

The improvement effect of graphene on the compressive strength of mortar was much better than that of the flexural strength at the same period, which indicated that graphene nanomaterials can enhance the compressive strength of mortar better, and rGO can greatly improve the strength and load bearing capacity of cement stone. Unlike graphene, GO had a greater effect on early flexural strength and late compressive strength

\section{Conclusion}

In accordance with the selected dispersion method, the nano-modified concrete was prepared after sufficient dispersion. The workability, mechanical properties and salt and frost resistance of nanomodified concrete were measured through the experimental method, and the following conclusions were obtained: under the same conditions, the ordinary concrete modified by nano - $\mathrm{SiO}_{2}$ and nano $\mathrm{Al}_{2} \mathrm{O}_{3}$, and fly ash concrete modified by nano - $\mathrm{SiO}_{2}$ and nano- $\mathrm{Al}_{2} \mathrm{O}_{3}$ had no obvious change in fluidity with unmodified concrete. Therefore, when the amount of admixture was less than 1\%, nanomaterials that mixed into concrete had no obvious influence on its workability. The fluidity of cement mortar modified by rGO/GO was also not significantly changed. Therefore, when the amount of admixture was less than $1 \%$, the nanomaterials were mixed into the concrete without obvious influence on its workability.

The compressive strength and flexural strength of concrete increased with the increase of nanomaterials. When the amount of admixture was $1 \%$, the compressive strength and flexural strength reached the maximum. Among them, nano - $\mathrm{SiO}_{2}$ was stronger than nano $-\mathrm{Al}_{2} \mathrm{O}_{3}$ in improving the mechanical properties of concrete, and rGO was stronger than GO.

Comparison of nano $-\mathrm{SiO}_{2}$ and nano $-\mathrm{Al}_{2} \mathrm{O}_{3}$ added into ordinary concrete and fly ash concrete respectively showed no significant difference in mechanical properties. Meanwhile, nano - $\mathrm{SiO}_{2}$ and nano $-\mathrm{Al}_{2} \mathrm{O}_{3}$ can improve the early strength of fly ash concrete. 


\section{Acknowledgement}

Research startup subject of Yangtze Normal Universi ty: 2017KYQD16

\section{References}

[1] N Salemi, K. Behfarnia. (2015). effect of Nanoparticles on Durability of Fiber-reinforced, Concrete Pavement[J]. Construction and Building Materials, 48, 934-941.

[2] A.S. Fai Uddin, W.M. Steve Supt. (2015) Chloride Induced Corrosion Durability of High Volume Fly Ash Concretes Containing Nano Particles[J]. construction and Building Materials, 99, 205-225.

[3] E.F. Guneyisi, M. Gesoglu, O.A. Azez, H. Oz. (2016). Effect of Nano Silica on the Workability of Selfcompacting Concretes Having Untreated and Surface Treated Lightweight Aggregates[J]. SCI, Construction and Building Materials, 115, 371380.

[4] H. Asgari, A. Ramezanianpour, H.J. Butt. (2016). Effect of Water and Nano-silica Solution on the Early Stages Cement Hydration[J]. Construction and Building Materials,129,11-24.

[5] A. Khaloo, M.H. Mobini, P. Hosseini. (2016). Influence of Different Types of Nano-SiO2 Particles on Properties of High-performance Concrete[J]. Construction and Building Materials, $113,188-201$.

[6] R. Ismael, J.V. Silva, R.N.F. Carmo, E. Soldado, E. Júlio. (2016). Influence of Nano-SiO2 and NanoAl203 Additions on Steel-to-Concrete Bonding[J]. Construction and Building Materials, 125, 10801092.

[7] J.V. Silva, R. Ismael, R.N.F. Carmo, E. Soldado, E. Júlio. (2016). Influence of Nano-SiO2and NanoAl203 Additions on the Shear Strength and the Bending Moment Capacity of RC Beams[J]. Construction and Building Materials, (123), 3546.
[8] S. Chithra, S.R.R. Senthil Kumar, K. Chinnaraju. (2016). The Effect of Colloidal Nano-silica on Workability, Mechanical and Durability Properties of High performance Concrete with Copper Slag as Partial Fine Aggregate[J]. Construction and Building Materials, 113, 794804.

[9] K. Kumari, R. Preetha, D. Ramachandran, V. Vishwakarma, C.S. Pillai. (2016). Nanoparticles for Enhancing Mechanical Properties of Fly Ash Concrete[J]. Materials Today: Proceedings, 3, 2387-2393.

[10] Y. Gao, B. He, Y. Li, J. Tang, L. Qu. (2017) Effects of Nano-particles on Improvement in Wear Resistance and Drying Shrinkage of Road Fly Ash Concrete[J]. Construction and Building Materials, 151, 228-235.

[11] T. Meng, Y. Yu, Z. Wang. (2017) Effect of NanoCa C3 Slurry on the Mechanical Properties and Micro-structure of Concrete with and without Fly Ash[J]. Composites Part B: Engineering, 117, 124129.

[12] S. Fallah, M. Nematzadeh. (2017). Mechanical Properties and Durability of High-strength Concrete Containing Macro-polymeric and Polypropylene fibers with Nano-silica and Silica Fume[J]. Construction and Building Materials, 132, 170-187.

[13] P. Zhang, J. Wan, K. Wang, Q. Li. (2017) Influence of Nano-Si 02 on Properties of Fresh and Hardened High Performance Concrete: A State-of-the-art Review[J]. Construction and Building Materials, 148, 648-658.

[14] D. Adak, M. Sarkar, S. Mandal. (2017). Structural Performance of Nano-silica Modified Fly-ash Based Geopolymer Concrete[J]. Construction and Building Materials, 135, 430-439.

[15] F.H. Nattaj, M. Nematzadeh. (2017). The Effect of Forta-ferro and Steel Fibers on Mechanical Properties of High-strength Concrete with and without Silica Fume and Nano-silica[J]. Construction and Building Materials, 137: 557572. 